\title{
PROCESSOS
}

\section{ARGUMENTATIVOS \\ EM ARTIGO DE OPINIÃO \\ DA OLIMPÍADA \\ DE LÍNGUA PORTUGUESA}

\section{PROCESOS ARGUMENTATIVOS EN EL ARTÍCULO DE OPINIÓN DE LAS OLIMPIADAS DE LA LENGUA PORTUGUESA}

\author{
ARGUMENTATIVE PROCESSES ON A OPINION ARTICLE OF THE PORTUGUESE LANGUAGE \\ OLYMPICS
}

\author{
Gilton Sampaio de Souza* \\ Universidade do Estado do Rio Grande do Norte \\ Francisca Lúcia Barreto de Lima Soares ${ }^{* *}$ \\ Secretaria de Educação do Estado do Ceará
}

\begin{abstract}
RESUMO: O presente estudo tem por objetivo analisar os diferentes tipos de argumentos, considerando-os partes centrais dos processos argumentativos, em artigos de opinião da Olimpíada de Língua Portuguesa (OLP), escritos sobre o tema "O lugar onde vivo". Para analisar os argumentos nos artigos selecionados, adotamos como base os pressupostos da Nova Retórica (PERELMAN; OLBRECHTS-TYTECA, 2005), associados aos estudos de Bakhtin $(2003,2010)$ e de Souza $(2003,2008,2009)$, dentre outros. Para tanto, selecionamos cinco artigos premiados em diferentes concursos $(2008,2010,2012)$, de domínio público, disponíveis no sítio oficial da Olimpíada. A maioria dos artigos estudados tem suas teses constituídas pelos argumentos que fundamentam a estrutura do real, com destaque para as relações de causa/efeito e de fato/consequência. Com base na ligação estabelecida entre os fatos, os oradores/articulistas procuram compreender essas relações e, ao mesmo tempo, explicar e justificar com argumentos as polêmicas que envolvem problemáticas relacionadas à sua vivência em comunidade.
\end{abstract}

PALAVRAS-CHAVE: Artigo de opinião. Discurso argumentativo. Nova Retórica. Olimpíada de Língua Portuguesa.

RESUMEN: Este estudio tiene como objetivo analizar los diferentes tipos de argumentos, teniendo en cuenta las partes centrales de los procesos argumentativos, en los artículos de opinión de la Olimpiada de la Lengua Portuguesa (OLP), escritos sobre el tema "El lugar donde vivo". Para analizar los argumentos en los artículos seleccionados, adoptamos como base teórica los presupuestos de la Nueva Retórica (PERELMAN; OLBRECHTS-TYTECA, 2005), asociados a los estudios de Bajtín $(2003,2010)$ y de Souza $(2003,2008$ y 2009), entre otros. Para ello, seleccionamos cinco artículos premiados en diferentes concursos (2008, 2010 y 2012), que son de dominio público, y están disponibles en el sitio oficial de la Olimpiada de la Lengua Portuguesa. La mayoría de los artículos tienen sus

\footnotetext{
* Professor de Linguística da Universidade do Estado do Rio Grande do Norte (UERN), Campus de Pau dos Ferros. Doutor em Linguística e Língua Portuguesa (UNESP/Araraquara). Líder do Grupo de Pesquisa em Produção e Ensino de Texto(GPET). E-mail: giltonssouza@gmail.com.

** Professora de Língua Portuguesa da rede estadual de ensino do Ceará, na cidade de Aracati. Mestre em Letras pelo Programa dePós-Graduaçãoem Letras (PPGL), da UERN, em Pau dos Ferros/RN. E-mail: luciablima@yahoo.com.br.
} 
tesis constituidas por los argumentos que fundamentan la estructura de lo real, destacando las relaciones de causa/efecto y hecho/consecuencia. Con base en la conexión establecida entre los hechos, los oradores/autores buscan comprender estas relaciones y, al mismo tiempo, explicar y justificar argumentos y polémicas que implican problemáticas relacionadas con su experiencia en la comunidad.

PALABRAS CLAVE: Artículo de opinión. Discurso argumentativo. Nueva Retórica. Olimpiadas de la lengua Portuguesa.

ABSTRACT: This study aims to analyze the different types of arguments, considering them central parts of argumentative processes, in opinion articles of the Portuguese Language Olympiad written on the topic "Where I live." To analyze the arguments in the selected articles we adopted the assumptions of the New Rhetoric (PERELMAN; OLBRECHTS-TYTECA, 2005), associated with the studies of Bakhtin $(2003,2010)$ and of Souza $(2003,2008,2009)$, among others. We selected five articles awarded in different competitions $(2008,2010,2012)$, which are in public domain, available on the official site of the Olympics. Most of the articles have their theses made by the arguments that support the actual structure, highlighting the relations of cause/effect and fact/consequence. Based on the established connection between the facts, speakers/ writers seek to understand these relationships and at the same time, explain and justify arguments and controversies involving issues related to their experience in the community.

KEYWORDS: Opinion article. Argumentative discourse. New Rhetoric. Portuguese Language Olympiad.

\section{INTRODUÇÃO}

As relações humanas tornam-se possíveis por meio do diálogo, o que implica a presença de sujeitos constituídos como parceiros, em situações de interação social, as quais se efetivam nos discursos. Nesse contexto, a ação de argumentar apresenta-se como fator essencial para o estabelecimento e para a manutenção de todo e qualquer tipo de relação comunicativa. À escola, como espaço de desenvolvimento de habilidades de leitura e de escrita, cabe a tarefa de ampliar o universo discursivo do aluno, favorecendo o seu diálogo com o mundo em que vive. Nessa perspectiva, estando clara a importância do trabalho com os gêneros textuais, este estudo investiga discursos oriundos do ambiente escolar, produzidos em sala de aula para atender a determinados fins que extrapolam os limites da sala ou mesmo da escola.

Trabalhamos com o artigo de opinião, por meio do qual o produtor defende seu ponto de vista sobre determinado assunto. Essas produções foram elaboradas a fim de participar de um concurso de textos de abrangência nacional, a Olimpíada de Língua Portuguesa (OLP), tendo sido, todos os artigos analisados, premiados nacionalmente nas Olimpíadas.

A pesquisa consiste, então, em analisar, nos artigos vencedores da OLP, os argumentos mais recorrentes, ou ainda aqueles que por sua força argumentativa dão sustentação aos processos argumentativos, apresentando-se como os principais argumentos mobilizados para a construção do discurso subjacente aos artigos. Para isso, constituímos como corpus $^{1}$ de análise cinco artigos de opinião, premiados nas OLP nos anos de 2008, 2010 e 2012, orientados pela temática “O lugar onde vivo”, proposta geral da OLP.

Os textos, recolhidos do site da $\mathrm{OLP}^{2}$, estão codificados seguindo uma ordem, com letra para indicar artigo (A), número para indicar a ordem (aleatória) de 1 a 5 e ano $(08,10,12)$. Ei-los: A1/08 (Cavaleiros da Cana versus Mecanização); A2/10 (Lobos disfarçados de cordeiros); A3/10 (A violência adentrou os muros de nossas escolas. E agora?); A4/12 (O Haiti é aqui); e A5/12 (Natal: noiva do sol, amante da prostituição).

Assim, por ser a Olimpíada de Língua Portuguesa (OLP) uma ação de resultados reconhecidos nacionalmente, caracterizada como uma proposta de intervenção nos diversos níveis de ensino na escola pública, a escolha dos artigos se justifica pela necessidade de

\footnotetext{
1 Os excertos dos artigos de opinião trabalhados neste trabalho e parte das análises aqui desenvolvidas são constitutivos da Dissertação de Mestrado "A argumentação em artigos de opinião das Olimpíadas de Língua Portuguesa”, de autoria de Francisca Lúcia Barreto de Lima Soares, defendida no Curso de Mestrado Acadêmico do Programa de Pós-Graduação em Letras (PPGL) da Universidade do Estado do Rio Grande do Norte (UERN), sob a orientação do professor doutor Gilton Sampaio de Souza, em dois de outubro de 2015.

2 Os artigos analisados como corpus da presente pesquisa podem ser acessados, na íntegra, no sítio oficial das Olimpíadas de Língua Portuguesa, no link: $<$ https://www.escrevendoofuturo.org.br>.
} 
analisar cientificamente produções consideradas exemplares; no caso deste estudo, por haverem utilizado os processos argumentativos de forma tão satisfatória que os classificou como vencedores num concurso de abrangência nacional.

Considerando ainda que OLP busca promover a melhoria no desenvolvimento da escrita, com base em uma proposta metodológica de gêneros do discurso, essa pesquisa justifica-se também por analisar artigos de opinião, em que o aluno é estimulado a opinar, a assumir uma postura sobre uma questão polêmica.

Determinada a importância do corpus estudado sob a perspectiva da Nova Retórica, buscamos apresentar aproximações com a obra de Perelman e Olbrechts-Tyteca (2005), além de outros autores como Reboul (2004), Meyer (2007), Abreu (2006) e Souza (2003, 2008, 2009).

Este artigo está organizado em cinco seções, assim distribuídas: a introdução, que acabamos de escrever, em que constam os objetivos, as justificativas e as questões metodológicas da pesquisa; a seção das orientações teóricas, sobre conceitos-chave da argumentação retórica, especialmente sobre as técnicas argumentativas e os tipos de argumentos a elas vinculados; a análise dos dados, em que os principais argumentos encontrados nos artigos de opinião são descritos e interpretados; e, por último, a conclusão, na qual retomamos os principais dados.

\section{ORIENTAÇÕES TEÓRICAS}

Ao produzir qualquer discurso, o orador/produtor do texto tem à sua disposição uma variada quantidade de recursos aplicáveis à elaboração de seus argumentos, à construção de sentidos sobre o objeto de seu texto. Nos estudos de argumentação retórica, alguns conceitos são essenciais para interpretação dos discursos e dos argumentos que lhe são subjacentes.

Para a Nova Retórica, a própria noção de discurso assume uma feição especial, uma orientação argumentativa, uma vez que

[...] o discurso é um ato que, como todo ato, pode ser objeto da parte de um ouvindo, de uma reflexão. [...] Os planos em que essa reflexão se situa serão, aliás, muito diversos. Ela poderá analisar o discurso como ato, como indício, como meio; poderá referir-se unicamente ao seu conteúdo, ou não descuidar de nenhum dos fatores que o constituem. Poderá notadamente referir-se à linguagem utilizada: enquanto o orador descrever o que 'viu', o ouvinte pensará talvez no significado psicológico ou fisiológico da visão. (PERELMAN; OLBRECHTSTYTECA, 2014, p. 213-214).

Assim, o discurso, para a Nova Retórica, é visto como indício, como meio de circular sentidos, espaço de produção de argumentos. Nessa perspectiva, todo discurso é argumentativo, sendo essa uma característica constitutiva da linguagem. Além disso, é pelo discurso que se efetivam os processos argumentativos, pois estes funcionam como mecanismos discursivos e retóricos produzidos por oradores/locutores. Nesses processos argumentativos estão em foco os próprios oradores, os argumentos apresentados, as técnicas e as teses, o auditório e o público-alvo a quem o orador se dirige. Neles, as teses se apresentam como proposições que anunciam o verdadeiro ou o falso sobre uma realidade concreta ou abstrata, articuladas aos demais elementos que constituem as argumentações nos mais diferentes discursos, orais ou escritos, em quaisquer gêneros e esferas da comunicação humana (SOUZA, 2008).

Nesses processos de discursivização e de ações retóricas, as técnicas argumentativas e os argumentos utilizados se apresentam como centrais, como eixo de toda orientação argumentativa. Perelman e Olbrechts-Tyteca (2005) propõem a classificação das técnicas argumentativas em quatro tipos de argumentos, a saber: argumentos quase-lógicos, argumentos fundados na estrutura do real e argumentos que fundam a estrutura do real, esses reunidos por associações de noções; somando-se ainda aos três os argumentos por dissociações de noções. 
O quadro a seguir apresenta de forma sintética os principais elementos do processo argumentativo, elaborado com base nos pressupostos teóricos de Perelman e Olbrechts-Tyteca (2005):

Quadro sinótico dos tipos de argumentos

\begin{tabular}{|c|c|c|c|}
\hline Grupos & $\begin{array}{c}\text { Técnicas } \\
\text { Argumentativas }\end{array}$ & \multicolumn{2}{|c|}{ Tipos de Argumentos } \\
\hline \multirow{12}{*}{$\begin{array}{l}\text { ASSOCIAÇÃO } \\
\text { DE NOÇÕES }\end{array}$} & $\begin{array}{c}\text { ARGUMENTOS } \\
\text { QUASE-LÓGICOS }\end{array}$ & \multicolumn{2}{|c|}{$\begin{array}{l}\text { a) Argumentos de contradição, da incompatibilidade e do } \\
\text { ridículo; } \\
\text { b) por identidade, definição, analiticidade e tautologia; } \\
\text { c) a regra de justiça e reciprocidade; } \\
\text { d) argumentos de transitividade, de inclusão e de divisão; } \\
\text { e) argumentos de comparação }\end{array}$} \\
\hline & \multirow{10}{*}{$\begin{array}{l}\text { ARGUMENTOS } \\
\text { FUNDADOS NA } \\
\text { ESTRUTURA DO } \\
\text { REAL }\end{array}$} & \multirow{5}{*}{$\begin{array}{l}\text { Ligações de } \\
\text { sucessão }\end{array}$} & Pragmático \\
\hline & & & Finalidade \\
\hline & & & Desperdício \\
\hline & & & Superação \\
\hline & & & Divisão \\
\hline & & \multirow{3}{*}{$\begin{array}{l}\text { Ligações de } \\
\text { coexistência }\end{array}$} & Autoridade \\
\hline & & & Prestígio \\
\hline & & & $\begin{array}{l}\text { Ruptura e } \\
\text { travagem }\end{array}$ \\
\hline & & \multirow{2}{*}{$\begin{array}{l}\text { Ligações } \\
\text { simbólicas }\end{array}$} & $\begin{array}{c}\text { Dupla } \\
\text { hierarquia }\end{array}$ \\
\hline & & & $\begin{array}{l}\text { Diferenças } \\
\text { de ordem }\end{array}$ \\
\hline & $\begin{array}{l}\text { ARGUMENTOS } \\
\text { QUE FUNDAM O } \\
\text { REAL }\end{array}$ & \multicolumn{2}{|c|}{$\begin{array}{l}\text { a) fundamento pelo caso particular } \\
\text { (exemplo, ilustração e } \\
\text { modelo/antimodelo); } \\
\text { b) raciocínio pela analogia. }\end{array}$} \\
\hline $\begin{array}{c}\text { DISSOCIAÇÃO } \\
\text { DE NOÇÕES }\end{array}$ & $\begin{array}{c}\text { PARES } \\
\text { HIERARQUIZADOS }\end{array}$ & \multicolumn{2}{|c|}{$\begin{array}{l}\text { a) aparência/realidade; } \\
\text { b) meio/fim; e } \\
\text { c) individual/universal. }\end{array}$} \\
\hline
\end{tabular}

Quadro 1: Quadro sinótico de tipos de argumentos na Nova Retórica

Fonte: Soares (2015)

Com base no quadro, buscamos especificar a essência desses argumentos, visto que servirão de subsídio para a análise dos textos que intentamos. 


\subsection{ARGUMENTOS QUASE-LÓGICOS}

A lógica fundamenta-se em raciocínios formais, utilizando-se de linguagem simbólica que se aproxima do raciocínio lógicomatemático, embora tirem sua força persuasiva de sua ligação a modelos de raciocínio incontestados (PERELMAN; OLBRECHTSTYTECA, 2005).

Os argumentos quase-lógicos se afastam dos raciocínios formais por permitirem variadas interpretações, visto que estão relacionados a circunstâncias sociais que não lhes permitem a simplificação própria dos processos puramente científicos. Ao contrário dos princípios lógicos da demonstração, apresentam-se passíveis de serem refutados, dado que não são "puramente lógicos”. Eis os principais:

a) Argumentos de contradição, de incompatibilidade e do ridículo - Na linguagem formal o absurdo resulta da contradição; na argumentação, no entanto, a incompatibilidade é apresentada para ser contornada e aceita a fim de que não se incorra no ridículo, que está para a argumentação assim como o absurdo está para a demonstração (REBOUL, 2004). Trata-se de uma afirmação que conflitua com uma opinião baseada na lógica, aceita pelo interlocutor; exemplo disso é a ironia, recurso que consiste em dizer o contrário do que, na verdade, deve ser dito.

b) Argumentos de identificação e definição, analiticidade e tautologia - A identificação de um termo em relação a outro já constitui em si um argumento quase-lógico, por ser o resultado de uma escolha por parte do orador. Pode ser completa ou parcial, e como sua elaboração implica um posicionamento, revela a subjetividade. Um dos elementos mais característicos da identificação é a definição, frequentemente utilizada quando se busca por meio da análise um direcionamento que objetiva afetar o outro, convencêlo ou persuadi- lo.

A definição é um tipo de argumento que se vale do raciocínio da significação, colocando em relação de identidade duas expressões: aquela cujo significado se pretende conhecer e outra que traz o significado da primeira. Mais do que simples artefato para a elaboração de textos puramente explicativos, ao contrário, constrói argumentos a partir da relação desses elementos. Um caso específico de identificação que merece ainda ser destacado é o da tautologia, que se baseia na repetição de termos, embora os significados sejam diferentes.

c) Argumento de regra de justiça e de reciprocidade - Embasados numa relação de simetria, os argumentos de reciprocidade visam à aplicação do mesmo tratamento a situações diferentes, despertando pela racionalidade de sua aplicação uma noção de justiça. É uma regra verificável na conduta diária, nas mínimas ações humanas em que se espera que o vínculo entre o antecedente e o consequente resulte em uma transferência de ponto de vista.

Assim, presumimos, por exemplo, que aqueles que fazem parte de um grupo social, de uma nação ou mesmo da raça humana devem gozar dos mesmos direitos e partilhar dos mesmos deveres. São noções formais fundamentadas na natureza das coisas que, no entanto, estabelecem-se nas relações argumentativas. Advém da regra de justiça classificarmos atitudes em justas ou injustas quando percebemos que posicionamentos ou ações foram tomados em escalas diferentes para situações idênticas. Por exemplo, no caso da parábola do filho pródigo, à primeira vista parece injusto receber com festa um filho que já tinha recebido sua herança enquanto o outro que ficou a serviço do pai não teve o mesmo tratamento.

d) Argumento de transitividade, de inclusão e de divisão - De acordo com os teóricos da Nova Retórica,

A transitividade é uma propriedade formal de certas relações que permite passar da afirmação de que existe a mesma relação entre os termos a e b e entre os termos b e c, à conclusão de que ela existe entre os termos a e c: as relações de igualdade, de superioridade, de inclusão, de ascendência são relações transitivas. (PERELMAN; OLBRECHTS-TYTECA, 2005, p. 257).

Fórum linguistic., Florianópolis, v.14, n.3, p.2251-2265, jul./ set.2017 
Esse argumento compreende a noção do todo a partir da soma de suas partes, numa relação quase matemática. Quando se parte da compreensão de que aquilo que não faz parte de nenhuma das partes não faz parte do todo, temos aí o argumento da divisão, o que na realidade só se verifica quando o todo e as partes são homogêneos.

e) Argumentos de comparação: os pesos, as medidas e as probabilidades - A comparação entre termos permite justificar um a partir de outro ou de outros da mesma categoria ou da mesma situação. Constitui-se como uma das formas mais recorrentes de argumentação na vida cotidiana. Trata-se de argumentos "[...] apresentados como constatações de fato, enquanto a relação de igualdade ou desigualdade afirmada só constitui, em geral, uma pretensão do orador" (PERELMAN; OLBRECHTS-TYTECA, 2005, p. 275). Mesmo confrontando realidades distintas, devem ser distinguidos tanto dos argumentos de identificação quanto do raciocínio por analogia. Podem ser citadas, como exemplo de comparação, as noções de peso e de medida, ainda que não façam referência à quantidade especificamente, mas ao efeito que podem assumir no jogo argumentativo.

As comparações também podem ser fundamentadas: i) por oposições, como quando se contrapõe o pesado ao leve; ii) por ordenação quantitativa, como quando se baseia em unidade de pesagem; e iii) por ordenamento, como quando se utiliza uma escala de peso (o mais pesado que). O argumento pelo sacrifício é o tipo de comparação que consiste em estabelecer o valor de uma coisa - ou de uma causa - pelos sacrifícios que são ou serão feitos por ela (REBOUL, 2004). Há ainda o argumento pela probabilidade que leva a considerar que uma escolha resulta da análise da frequência de resultados positivos a ela associados.

\subsection{ARGUMENTOS FUNDADOS NA ESTRUTURA DO REAL}

Os argumentos que se baseiam em situações concretas, experimentadas na vida real, não se relacionam à lógica, mas se fundamentam na experiência, nos elos reconhecidos entre as coisas. Recorre-se a eles utilizando-se aquilo que é aceito ao que se pretende admitir. De acordo com Perelman e Olbrechts-Tyteca (2005), "Desde que haja elementos do real associados uns aos outros numa ligação reconhecida, é possível fundar nela uma argumentação que permite passar daquilo que é admitido ao que se quer admitir". Depreende-se desse pressuposto a possibilidade dessas estruturas produzirem efeitos de sentido dependendo da orientação argumentativa, quer como fatos, quer como verdade, quer como presunção. Vejamos:

a) Ligações de sucessão - Essas relações se caracterizam pela busca de justificativas, causas e explicações para as teses que se busca defender. Para construí-las, recorre-se às relações de causa/efeito, de consequência/finalidade etc. Analisando os fatos de acordo com tais relações, vale destacar alguns argumentos que se baseiam nessas ligações: i) argumentos pragmáticos - que avaliam um fato ou acontecimento a partir de consequências favoráveis ou desfavoráveis; ii) argumentos por finalidade - "[...] são fundados na ideia de que o valor de uma coisa depende do fim cujo meio é ela" (REBOUL, 2004, p. 175); iii) argumentos pelo desperdício - justificam a conclusão de algo sem sucesso pelo fato de ter sido iniciada. Ainda há o argumento de superação, que "[...] consiste em seguir sempre, em ir além para conquistar um crescimento constante. E, finalmente, o argumento de direção, que consiste em rejeitar uma coisa mesmo admitindo que é inofensiva ou boa - porque ela serviria de meio para um fim que não se deseja” (REBOUL, 2004, p. 175).

b) Ligações de coexistência - Com o intuito de unir elementos da mesma natureza, as ligações de coexistência relacionam os atributos à essência e os atos a pessoas. Esses argumentos visam estabelecer uma relação entre realidades diferentes, como, por exemplo, se atribui a alguém que tem uma qualidade ou um defeito a partir da observação de atos, constituindo o argumento de pessoa. Nesse raciocínio encontramos o argumento de autoridade, que se baseia em atos ou no prestígio de uma pessoa ou de um grupo de pessoas e cujo valor social serve como recurso de prova para sustentar uma tese. E há, ainda, o recurso de prestígio, que se fundamenta no prestígio moral, entre outros, de alguém que pode estimular outras pessoas a imitá-lo.

Na contramão do argumento de autoridade, cabe destacar as técnicas de ruptura e travagem que se estabelecem a partir de relações antagônicas entre as pessoas e suas ações. Para Reboul (2004, p.178), essa técnica (argumento ad hominem) "[...] consiste em refutar uma proposição, recorrendo a uma personalidade odiosa [...] ou então ressaltando as fraquezas de quem o enuncia”.

$\mathrm{Na}$ verdade, as técnicas de ruptura e travagem objetivam refrear a construção de um juízo de valor com base em preconceitos existentes entre o ato e a pessoa, o que impediria o auditório de aceitar os argumentos do orador. Perelman e Olbrechts-Tyteca (2005) 
propõem que a interação entre o fato e a pessoa seja posta em ação quando existir uma incompatibilidade entre o que julgamos da pessoa e o que pensamos do ato.

c) Ligações simbólicas - Embora os significados dos símbolos mudem de acordo com o meio, as ligações simbólicas, por seu valor sociocultural, apresentam-se frequentemente associadas às ligações de coexistência, consistindo na aceitação de determinados valores em detrimento de outros. Como exemplo podem ser citados os símbolos que representam as religiões, a pátria, as agremiações esportivas, entre outros.

A escala de valores que se estabelece entre os termos constitui o argumento de dupla hierarquia em que um se sobrepõe a outro, já admitidos pela sociedade. Reboul (2004, p. 179) cita um exemplo dado por Aristóteles ao dizer que: "O que pertence a um deus é preferível ao que pertence a um homem, o que pertence à alma é preferível ao que pertence ao corpo”.

A dupla hierarquia se constrói no estabelecimento de uma escala de valores entre os termos, em relação à escala já admitida pela sociedade. Ainda como argumento de hierarquia há o argumento a fortiori, que considera o que está com maior razão, enquanto serve-se do limite entre as hierarquias para escolher uma das duas. E, finalmente, há os argumentos por diferenças de grau e de ordem, relativos às noções quantitativas (diferenças de grau) e qualitativas (diferenças de ordem).

\subsection{ARGUMENTOS QUE FUNDAM A ESTRUTURA DO REAL}

Ainda que não se apoiem na estrutura do real, essas técnicas também são empíricas, na verdade criam ou pelo menos a completam, estabelecendo nexos não vistos ou não suspeitados entre as coisas. Partem de um fato particular para a construção de generalizações, com argumentos indutivos. Este argumento vai do fato à regra, podendo ser subdividido em: fundamentos pelo caso particular (exemplo, ilustração, modelo/antimodelo) e raciocínio por analogia. Os primeiros baseiam-se na relação entre estruturas enquanto que a analogia baseia-se nas semelhanças entre coisas de natureza diferentes. Vejamos:

a) Argumento pelo exemplo, por ilustração e por modelo/antimodelo - Quando o orador utiliza um exemplo como argumento, na realidade busca fundamentar uma tese já conhecida pelo auditório. Essa deve ser de caráter incontestável, visto que deve levar a uma conclusão. Perelman e Olbrechts-Tyteca (2005, p. 405) defendem que "Um caso particular observado, jamais pode estar em contradição absoluta com um juízo cuja universalidade é empírica. Ele só pode reforçá-lo ou enfraquecê-lo”.

A argumentação pela ilustração funciona como recurso de presença e, de acordo com Souza (2008, p. 64), "[...] se o exemplo busca a incontestação do fato, porque pretende fundamentar, a ilustração busca impressionar, mexer com a imaginação, porque parte de uma regra reconhecida socialmente".

É fácil confundir o argumento pela ilustração com o argumento pelo exemplo; no entanto, o primeiro fundamenta a regra, enquanto o último utiliza fatos ou eventos particulares a fim de "reforçar a adesão a uma regra conhecida e aceita" (PERELMAN; OLBRECHTS-TYTECA, 2005, p. 410). Outra diferença é o fato de que o argumento por ilustração pode representar algo fictício, duvidoso e induzir à generalização, enquanto o argumento pelo exemplo de forma alguma pode ser refutado. O argumento pelo modelo consiste em sugerir a imitação de determinadas ações, como na admiração que alguém exerce sobre o orador, com base em condutas ou ações que lhe conferem prestígio social. "Se a referência a um modelo possibilita promover certas condutas, a referência a um contraste, a um antimodelo permite afastar-se delas" (PERELMAN; OLBRECHTS-TYTECA, 2005, p. 407). Essa assertiva sugere algo a ser evitado, um antimodelo, relacionado a alguém cujas ações fogem dos padrões de comportamento aceitos pelo auditório.

b) Argumento por analogia - Segundo Reboul (2004, p. 185), "Raciocinar por analogia é construir uma estrutura do real que permita encontrar e provar uma verdade graças a uma semelhança de relações”. A analogia é estabelecida a partir da semelhança entre dois pares de termos, ainda que estes sejam de realidades diferentes. Na relação analógica, "a" está para "b” assim como "c" está para "d". A analogia vai além da simples comparação, uma vez que lida com uma realidade concreta e outra abstrata, enquanto a comparação 
lida apenas com realidades concretas. O objetivo desse tipo de argumento é esclarecer o "tema" - aquilo que se quer provar, algo abstrato - a partir do concreto, o "foro". É em suma uma busca pela verdade dos fatos a partir de semelhanças de relações.

Quando a analogia permite expressar elementos do tema e do foro com omissão de outros, configura-se como metáfora. A metáfora tem caráter argumentativo quando é empregada em função da defesa de uma tese ou opinião, de outra forma restringe-se seu uso ao estilo de texto. Segundo Perelman e Olbrechts-Tyteca (2005), a fusão do domínio do tema e do foro, quando tem como objetivo criar uma emoção poética, melhor se presta a essa relação e os tornam praticamente indissociáveis.

\subsection{ARGUMENTOS POR DISSOCIAÇÃO DE NOÇÕES}

Até este ponto foram apresentadas técnicas relativas à associação de noções ou de elementos aparentemente independentes. Ao contrário dessas, existem ainda técnicas que buscam de alguma forma dissociar ou romper noções estabelecidas em pares hierarquizados, a fim de dissipar incompatibilidades com base na constatação de que todo discurso pode se contrapor a outro.

Esses argumentos pretendem remover a incompatibilidade de uma tese, por meio da decomposição de um conceito, buscando apresentar uma visão coerente com a realidade. Entre os pares construídos hierarquicamente em nossa cultura podem ser citados, segundo Reboul (2004): meio/fim, consequência/princípio, ocasião/causa, relativo/absoluto, subjetivo/objetivo, múltiplo/uno, normal/normativo, individual/universal, particular/geral, teoria/prática, linguagem/pensamento, letra/espírito.

O par hierarquizado aparência/realidade é o mais representativo da dissociação de noções, que permite com que sejam vistas duas realidades, uma aparente e uma verdadeira, uma vez que nem sempre a realidade aparente é, de fato, verdade. Perelman e OlbrechtsTyteca (2005) citam o exemplo de um bastão que, mergulhado parcialmente na água, torna-se aparentemente curvo quando se olha, e reto quando se toca. Duas realidades incompatíveis, pois uma é real, a outra é apenas aparência.

O estudo das técnicas argumentativas cumpre a função de possibilitar o conhecimento dos elementos retóricos implicados na elaboração e na defesa de suas teses, embora fique claro que essas técnicas são passíveis de falhas, podendo ser refutadas. Para Reboul (2004, p. 194), “[...] não se espera de um argumento apenas que ele seja eficaz, isto é, que seja capaz de persuadir seu auditório; esperase que ele seja justo, isto é capaz de persuadir qualquer auditório, de dirigir-se ao auditório universal”.

\section{ANÁLISE DOS DADOS: ARGUMENTOS EM ARTIGOS DE OPINIÃO}

Teceremos neste ponto do estudo algumas considerações sobre o processo de escolha que leva o aluno a optar por determinado tipo de argumento no intuito de convencer o leitor sobre a validade de sua tese. Sabemos que nesse processo precisamos considerar um conhecimento prévio em que se manifesta o diálogo com o mundo, visto que o discurso, por seu caráter dialético, dialógico e argumentativo (BAKHTIN, 2003; PERELMAN; OLBRECHTS-TYTECA, 2005), é imprescindível à interação humana nas mais variadas formas de comunicação. Buscamos destacar, na análise, os argumentos mais utilizados, considerando as técnicas argumentativas definidas por Perelman e Olbrechts-Tyteca (2005), a fim de verificar o domínio com que o aluno emprega alguns dos principais argumentos discutidos nos estudos da Nova Retórica e observados em discursos de diferentes gêneros e esferas da comunicação humana.

Com base no tema "O lugar onde vivo", o aluno teve a possibilidade de escolher o assunto sobre o qual escreveu o artigo, expondo uma questão polêmica, cujo posicionamento assumido revela os efeitos de sentidos que deseja imprimir às suas teses e ao auditório que pretende atingir com sua argumentação. Nesse caso, o auditório particular se constituía por banca formada pelos organizadores da Olimpíada de Língua Portuguesa, que iriam corrigir os artigos de opinião levando em consideração as regras e os critérios preestabelecidos.

A análise prévia dos artigos de opinião apontou para estruturas similares nos processos argumentativos, com destaque para a presença de alguns tipos de argumentos que ganharam visibilidade, especialmente por serem artigos premiados na OLP. 
Iniciaremos a análise tomando por base os argumentos fundados na estrutura do real. Esses argumentos partem da experiência nas ligações existentes entre as coisas do mundo real, partem do que é aceito àquilo que se quer fazer admitir. Sua recorrência no corpus pode ser explicada, também, pelo fato de serem encontrados no uso comum e de se referirem a convenções. Não se prendem à descrição objetiva da realidade, mas àquilo que a ela se relacionam: fatos, verdades ou presunções. Partem daquilo que já é admitido ao que se pretende estabelecer.

Vejamos os mais significativos, por sua utilização nos artigos estudados, enfatizando que a seleção dos fragmentos busca contemplar da forma mais igualitária possível os cinco textos, com base na recorrência ou na força argumentativa.

Excerto 1: Argumentos pragmáticos ${ }^{3}$

A512 - Título: Natal, noiva do sol, amante da prostituição

[...] A prostituição é um problema de ordem social e coletiva e, nesse contexto, é preciso a formação de uma aliança entre os cidadãos potiguares e as instituições públicas responsáveis no intuito de que sejam elaboradas medidas que evitem a entrada de novas mulheres e jovens nesse mercado ilícito, tais como a fundação de mais escolas técnicas, no ímpeto de profissionalizá-las. (NOVAIS, 2012).

Dentre os mais utilizados, o argumento pragmático se destaca por avaliar um fato pelas suas consequências positivas ou negativas (PERELMAN; OLBRECHTS-TYTECA, 2005), donde se pressupõe a força argumentativa que ele exerce sobre o auditório. Em A5/12, visualizando a possibilidade de, no futuro, "novas mulheres e jovens" não precisarem adotar a prostituição como alternativa para a falta de emprego, o autor aponta a formação de uma aliança entre diversos segmentos da sociedade como uma possível solução para o problema. Aqui é a consequência favorável que se enfatiza, para se defender a criação de uma força-tarefa a fim de empreender uma busca de solução para o problema.

Excerto 2: Argumento causal

\section{A2/10 - Título: Lobos disfarçados de cordeiros}

[...] Além disso, acredito que essa tentativa de associar a pedofilia ao celibato seja um ataque direto à Igreja Católica, pois sabemos bem a influência que ela exerce, mesmo nos dias atuais, sobre os conceitos de moralidade e valores da população católica, que ainda é maioria no mundo. (SANTOS, 2010).

Nos artigos estudados, a grande utilização de argumento de sucessão por vínculo causal pode ser explicada pelo fato de que o orador frequentemente usa esse tipo de argumento quando, por meio do conhecimento de um fato, pretende aumentar ou diminuir a crença na existência de uma causa que o explique ou de um efeito que dele resulte (PERELMAN; OLBRECHTS-TYTECA, 2005).

No excerto A2/10, o autor defende a tese de que o ataque à Igreja Católica, sob a alegação de pedofilia, deve-se ao fato de esta exercer reconhecida preponderância em número de adeptos no mundo inteiro. Resulta daí, como consequência e efeito de sentido, que outras instituições passem a atacá-la com o intuito de descredibilizá-la, especialmente no que se refere aos conceitos de moralidade. A perda de credibilidade resultaria em uma abertura de espaços para aqueles que pretendem divulgar "os conceitos de moralidade e valores" ou defendê-los sob outra ótica.

\footnotetext{
${ }^{3}$ Os artigos de opinião que constituem o corpus da presente pesquisa estão com as referências de seus autores e podem ser acessados, na íntegra, no sítio oficial da Olimpíada de Língua Portuguesa, no link: <https://www.escrevendoofuturo.org.br > e/ou nos links individuais dos livros com publicação dos textos finalistas de cada ano, conforme expostos nas Referências deste trabalho.
} 
Excerto 3: Argumento de autoridade

A210 - Título: Lobos disfarçados de cordeiros

[...] Em um artigo para o jornal Le Monde o renomado teólogo católico Hans King, suíço-alemão, presidente da Fundação Ética Mundial, se pergunta: "Qual é a melhor formação para as gerações futuras de padres?", e ele mesmo responde: "A abolição da regra do celibato, raiz de todos os males, e a abertura da ordenação às mulheres". Para ele o celibato é a principal causa dos escândalos ocorridos na Igreja e pelo déficit do número de padres. (SANTOS, 2010).

Citando um jornal de renome internacional, o autor de A2/2010 estabelece um acordo com o auditório, como tese inicial, em que a pressuposição da seriedade deste veículo seja um requisito para validar a autoridade do teólogo católico citado, cuja voz se levanta em defesa da extinção do celibato. Podemos perceber aí uma combinação de premissas: primeiro a autoridade impessoal representada pelo jornal Le Monde, conhecido internacionalmente, depois a autoridade designada pelo cargo de presidente de uma fundação ética, que confere ao teólogo a credibilidade necessária para opinar sobre o tema e, finalmente, ao cargo que ocupa na ordem religiosa, o que mais autoriza seu ponto de vista, uma vez que se trata de um católico com alto grau de conhecimento, posicionando-se contrariamente a uma questão-problema da própria igreja a que serve.

Essas referências visam atestar a validade e a pertinência da posição e autoridade assumidas pelo teólogo, cuja menção ao nome certamente não surtiria o mesmo efeito argumentativo caso se tratasse de uma personalidade representativa de outra área que não a religiosa, especialmente ligada à igreja em questão. Vale ressaltar que o argumento de autoridade a que nos referimos foi apresentado como contra-argumentação no artigo em análise, o que lhe dá mais força ao processo argumentativo como um todo.

Excerto 4: Argumento pela interação ato/pessoa

A4/12 - Título: O Haiti é aqui

[...] Alguns haitianos vieram pensando em ganhar dinheiro e, em seguida, retornar à sua terra natal. Entretanto, sem documentos para comprovar escolaridade, alguns se depararam com métodos de contratação racista, em que, segundo um representante de uma empresa: "Trabalhador bom é aquele que tem canela fina. Não vamos contratar quem tem panturrilha grossa porque é preguiçoso". (FIGUEIREDO, 2012).

Em A4/12, a relação ato/pessoa é estabelecida a partir da referência a uma característica física. O orador recorre, nesse caso, ao senso comum, ao diálogo com o discurso popular de que "Trabalhador bom é aquele que tem canela fina”, a fim de validar uma opinião. Atrelar a contratação de um trabalhador a um atributo físico pode parecer até um argumento pelo ridículo, uma vez que carece de fundamentação científica e contraria o que é estabelecido por lei como requisitos necessários para a contratação de mão de obra. Como o intuito do orador é defender a tese de que é preciso criar oportunidades de socializar os imigrantes haitianos, o argumento é apresentado a fim de ser refutado. Assim ele mostra que a voz e os argumentos de "um representante da empresa" carecem de credibilidade, especialmente por estar amparada em um argumento do senso comum. Os argumentos analisados apresentam um ponto de vista ou se detêm em interpretar a realidade, estabelecendo uma relação direta entre as proposições assumidas e as pessoas que as assumem.

Além dos argumentos fundados na estrutura do real, ganharam visibilidade nos cinco artigos analisados os artigos quase-lógicos, aqueles que mantêm semelhança com a Lógica Formal, mas que não são propriamente lógicos, são quase-lógicos.

Excerto 5: Argumento por definição

A3/10 - Título: A violência adentrou os muros de nossas escolas. E agora?

[...] A violência pode ser designada como uma transgressão da ordem e das regras da vida em sociedade, e esse conceito se aplica com eficácia ao que tem se visto ultimamente em nossa Cruzeiro do Sul, cidade que, apesar de pequena, já vivencia tramas outrora associadas mais a grandes metrópoles, como assaltos, assassinatos, estupros, entre outros. (SOUZA, 2010). 
Em A3/10, o autor, apoiado em uma definição descritiva, caracteriza como violenta a situação vivida pelos moradores de Cruzeiro do Sul, partindo de uma definição que pode ser considerada como argumento quase-lógico, pois a escolha de um termo em relação a outro nunca revela uma identidade pura, sendo sempre uma opção do orador a sua utilização (SOUZA, 2008). O tipo de argumento por definição se apresenta como constitutivo da técnica dos argumentos quase-lógicos e se constitui bastante eficaz na defesa de uma ideia, dado este que, enquanto confere ao autor um certo grau de conhecimento, também pode ser utilizado como forma de afetar o outro, buscando a persuasão.

Excerto 6: Argumento por contradição e incompatibilidade

A4/2012 - Título: O Haitié aqui

[...] Alguns acrianos acreditam que o dinheiro deveria ter sido aplicado em infraestrutura nos bairros rio-branquenses, em vez de ser destinado a suprir as necessidades dos haitianos. Afinal, ao mesmo tempo em que o Acre recebia de braços abertos os estrangeiros, os moradores da capital acriana passavam por uma grande calamidade: a maior alagação de todos os tempos ocorrida com o transbordamento do rio Acre-25\% de nossa cidade ficou debaixo d'água. (FIGUEIREDO, 2012).

Para a defesa das teses que se baseiam em defender as descontinuidades envolvidas nas contradições, os argumentos quase-lógicos são largamente utilizados. No excerto destacado de A4/2012, o autor expõe a situação de calamidade vivida pela população de Rio Branco-AC devido a uma enchente. Em seguida, apresenta a contradição que se estabelece com o apoio dado aos estrangeiros que ali chegaram, fugindo também de uma situação calamitosa (terremoto) ocorrida em seu país em busca de ajuda naquele estado. Esse posicionamento, no entanto, contraria o que o autor defende na tese principal, que é justamente prestar ajuda humanitária a essas pessoas que vivem um drama parecido com o seu. Em verdade, utiliza-o como estratégia para construir sua argumentação num discurso crítico de respostas aos discursos contrários à tese defendida. Os argumentos de contradição e incompatibilidade são utilizados quando se objetiva invalidar o argumento adversário para fundamentar sobre ele argumentos que o orador julga capaz de convencer o auditório.

Tanto os argumentos quase-lógicos como argumentos que se fundam na estrutura do real apresentaram recorrência considerável nos artigos em geral, mas em especial naqueles dos quais retiramos os excertos para a análise. Além desses argumentos, observamos, ainda, os argumentos que partem de fatos particulares para construir generalizações. São os argumentos que fundam a estrutura do real.

Excerto 7: Argumento por exemplo, pelo caso particular

A3/10 - Título: Violência adentrou os muros de nossas escolas. E agora?

[...] Por isso, considero positivas ações como a passeata realizada há poucos dias pelas escolas Maria Lima e Craveiro Costa nos bairros onde estão instaladas, Remanso e Cohab, considerados os mais violentos do município e que interferem no dia a dia dessas escolas, através de vândalos e agressores que invadem as suas dependências. (SOUZA, 2010).

No Excerto 7, do artigo de opinião A3/10, a realização de uma passeata como iniciativa das escolas nas comunidades onde se situam, e que são bairros reconhecidamente violentos de Cruzeiro do Sul, aparece como exemplo de ações que o orador julga capazes de contribuir positivamente para a solução do problema da violência na escola. As ações dessas escolas contra a violência se tornam exemplos, casos particulares, que justificam o seu argumento fundado na estrutura do real. O argumento faz pressupor que uma ação concreta pode chamar a atenção dos moradores desses bairros e provocar uma possível mudança de conduta.

Excerto 8: Argumento por analogia

A1/08 - Título: Cavaleiros da cana versus mecanização

[...] Devido ao serviço árduo e estafante, podemos chamá-los de cavaleiros da cana, pois levantam de madrugada, vestem suas armaduras e saem para a luta com a determinação de guerreiros. (OLIVEIRA, 2008). 
No artigo de opinião A1/08, nesse excerto analisado, é a figura do cavaleiro medieval que se associa à imagem do cortador de cana, ressaltando-lhe qualidades como determinação, força, coragem e disposição para o combate diário na lida, que está, no texto, relacionada à luta do cavaleiro medieval. Há uma analogia entre as duas realidades, em que cavaleiro medieval e o cortador de cana assumem posições similares. Com isso, o argumento por analogia traz as imagens até grandiosas que as pessoas, em geral, têm dos cavaleiros medievais para serem aplicadas aos cortadores de cana, dando a estes um maior valor nos argumentos em sua defesa.

Por último, após analisarmos alguns tipos de argumentos, os mais recorrentes nos artigos de opinião, vinculados às técnicas argumentativas por associação de noções (quase-lógicos, baseados na estrutura do real e que fundamentam a estrutura do real), veremos a seguir um argumento utilizado por dissociação de noções que, embora menos utilizado, também se fez presente entre os tipos de argumentos que deram estruturação aos artigos de opinião analisados por seu valor argumentativo, capaz de direcionar a discussão.

Excerto 9: Argumento por dissociação de noções

A1/08 - Título: Cavaleiros da cana versus mecanização

[...] Na minha opinião, os impactos negativos causados pelas queimadas são inegáveis, mas não deveriam servir de justificativa para a substituição de trabalhadores por máquinas. Vale lembrar que o corte da cana sem a prática da queimada não é impossível, pois isso já ocorre quando há o corte de cana para a produção de mudas. (OLIVEIRA, 2008).

O artigo A1/2008 versa sobre os impactos provocados pelas queimadas nas lavouras, que têm constituído desde sempre uma preocupação quanto à preservação do solo em que são cultivadas. É fato que a produção de cana de açúcar gera grande quantidade de resíduos, os quais precisam ser descartados a fim de preparar o solo para o plantio de novas lavouras. O excerto analisado do A1/08, "os impactos negativos causados pelas queimadas são inegáveis, mas não deveriam servir de justificativa para a substituição de trabalhadores por máquinas", destaca que os produtores nela se amparam para realizar essa prática condenada pelas autoridades ambientais, mas largamente utilizada por facilitar o custo para os produtores.

Buscando invalidar a incompatibilidade presente nesse conceito do qual se podem depreender duas realidades, como afirma Reboul (2004, p. 189), "[...] onde se via uma realidade, surgem duas, a aparente e a verdadeira”. No caso, o orador busca confrontar as teses, afirmando que essas realidades não constituem relações indissolúveis, pois já ocorre o corte da cana sem a necessidade de queimadas, utilizando-se os cortes como mudas. Isso certamente demanda mais trabalho e mais tempo, por isso talvez não sejam tão apreciadas. Assim, o corte de cana não justifica em si as queimadas, é preciso dissociar essa relação de ideias muito frequente. As queimadas dão-se por um tipo de corte de cana específico, e não em qualquer corte de cana.

\section{CONCLUSÃO}

Neste trabalho, analisamos artigos de opinião com enfoque nos argumentos mobilizados na defesa das teses, buscando interpretar os argumentos mais frequentes e os sentidos atribuídos pelos alunos oradores às questões polêmicas relativas à sua vivência, considerando aspectos relacionados a "O lugar onde vivo", tema dado para produção dos artigos que concorreram às Olimpíadas de Língua Portuguesa. Para tanto, seguimos o passo a passo que julgamos necessário para atender aos objetivos desse trabalho. Uma vez que os elementos da argumentação se apresentam intimamente ligados, consideramos pertinente estabelecer uma correlação entre eles, como fatores que constituem um todo no processo da defesa de tese e de construção dos argumentos que deram sustentação a todos os processos argumentativos inerentes aos artigos de opinião analisados, que foram também considerados como os melhores artigos nos anos de 2008, 2010 e 2012.

Os recursos argumentativos utilizados para a defesa das teses permitem-nos afirmar que, além do seu papel comunicativo, atendem aos objetivos propostos para a construção de um artigo cuja utilização, se não for suficiente para convencer seu(s) auditório(s), serve pelo menos para fundamentar sua posição diante de um assunto. Com base em um trabalho sistematizado, o primeiro ponto considerado por nós, no trabalho da OLP, é exatamente o tema geral, capaz de permitir um olhar sobre questões ligadas ao espaço 
em que habita, a problemas enfrentados por ele, por sua família, por sua comunidade ou mesmo de abrangência mundial, como é o caso da pedofilia ligada à vida religiosa. A proposta possibilita ao aluno opinar, só que de uma forma orientada, conhecendo os principais tipos de argumentos que estão à sua disposição, como parte do mundo real, das experiências do dia a dia, ou como parte dos valores e relações lógicas e/ou quase formais que marcam as ideias e os raciocínios desenvolvidos nesses artigos de opinião.

Dentre os argumentos e técnicas utilizados para construírem seus processos argumentativos, prevalecem os argumentos fundados na estrutura do real, que estabelecem ligações entre elementos do mundo concreto, daquilo que tem existência comprovada ao que se espera fazer admitir. Tratam-se de fatos, verdades, presunções, presentes no cotidiano, do mundo comum, resultantes de convenções. Destacamos nessa técnica a grande recorrência ao argumento pragmático, empregado com a finalidade de avaliar um fato por suas consequências positivas ou negativas. Esse tipo de argumento funciona como ancoragem à tese principal defendida nos artigos de opinião, vinculada ao tema central dos artigos, especialmente porque se fundamenta em fatos cotidianos, assuntos que na maioria das vezes afetam o orador diretamente.

Os argumentos pragmático e causal foram identificados em todos os cinco textos, seguidos pelo argumento de autoridade, que aparece em três. Os argumentos de contradição/incompatibilidade e analogia aparecem em dois. Destacamos, ainda, por sua carga persuasiva, os argumentos de definição, de ato/pessoa e pelo caso particular, que foram utilizados somente em um dos artigos.

Ressaltamos, também, o argumento de dissociação de noções, cujo emprego revela um posicionamento divergente, um engajamento com o problema que, para o orador, precisa ser melhor explicitado e trazido à reflexão, como é o caso da associação da pedofilia ao celibato e do turismo ao progresso.

Desse modo, esta pesquisa pretende não somente ser uma contribuição para os estudos em argumentação, sobretudo em Nova Retórica, com base em uma ação interventiva, como é a OLP, mas também buscar a compreensão da forma como o aluno constitui seu discurso, em um gênero muito utilizado na sociedade, para a defesa de um ponto de vista. Esperamos, assim, colaborar com novos pesquisadores em futuros estudos que tenham como finalidade os processos argumentativos, com vistas a promover uma reflexão sobre o ensino da escrita, para os estudos em argumentação, com destaque para o ensino-aprendizagem da produção textual na escola pública.

\section{REFERÊNCIAS}

ABREU, A. S. A arte de argumentar: gerenciando razão e emoção. 9. ed. São Paulo: Ateliê Editorial, 2006.

BAKHTIN, M. M. Marxismo e filosofia da linguagem. São Paulo: Martins Fontes, 2010.

BAKHTIN, M. M. Estética da criação verbal. 4. ed. São Paulo: Martins Fontes, 2003.

BRAIT, B. Bakhtin e a natureza constitutivamente dialógica da linguagem. In: BRAIT, B. (Org.). Bakhtin, dialogismo e construção de sentido. 2. ed. São Paulo: Editora da UNICAMP, 2005. p. 91-104.

BRASIL. Ministério da Educação. Secretaria de Educação Média e Tecnológica. Parâmetros Curriculares Nacionais (Ensino Médio). Brasília: MEC/SEF, 2000.

DOLZ, J; SCHNEUWLY, B. Gêneros e progressão em expressão oral e escrita - elementos para reflexões sobre uma experiência suíça (Francófona). In: Gêneros orais e escritos na escola. Campinas: Mercado das Letras, 2004. p. 41-70. 
FIGUEIREDO, P. R. Textos finalistas. Pontos de vista: caderno do professor. In: BRASIL. Ministério da Educação. Olimpíada de língua portuguesa: escrevendo o futuro. São Paulo: Cenpec, 2012. Disponível em:< https://www.escrevendoofuturo.org.br/EscrevendoFuturo/arquivos/1894/2012_livro.pdf>. Acesso em: 20 maio 2017.

MARCUSCHI, L. A. Produção textual, análise de gêneros e compreensão. São Paulo: Parábola Editorial, 2008.

MEYER, M. A retórica. São Paulo: Ática, 2007.

NOVAIS, T. C.Textos finalistas. Pontos de vista: caderno do professor. In: BRASIL. Ministério da Educação. Olimpíada de língua portuguesa: escrevendo o futuro. Textos finalistas. Pontos de Vista: caderno do professor. São Paulo: Cenpec, 2012. Disponível em. $<$ https://www.escrevendoofuturo.org.br/arquivos/1894/2012-livro.pdf>. Acesso em: 20 maio 2017.

OLIVEIRA, M. C. Textos finalistas. Artigo de opinião. In: BRASIL. Ministério da Educação. Olimpíada de Língua Portuguesa: escrevendo o futuro. São Paulo: Cenpec, 2008. Disponível em: <https://www.escrevendoofuturo.org.br/arquivos/2978/livroopiniao-finalistas-2008.pdf>. Acesso em: 20 maio 2017.

PERELMAN, C.; OLBRECHTS-TYTECA, L. Tratado da argumentação: a Nova Retórica. Tradução de Maria Ermentina Galvão. São Paulo: Martins Fontes, 2005.

POSSENTI, S. Gêneros discursivos: Bakhtin vai à escola. In: ARANHA, S. D. de G. et al. (Org.). Gêneros e linguagens: diálogos abertos. João Pessoa: Editora Universitária da UFPB, 2009. p. 9-20.

RANGEL, E. O.; GAGLIARDI, E.; AMARAL, H. Pontos de vista: caderno do professor. São Paulo: Cenpec, 2010.

REBOUL, O. Introdução à retórica. Tradução de I. C. Benedetti. São Paulo: Martins Fontes, 2004.

SANTOS, M. S. Textos finalistas. Artigo de opinião: caderno do professor. In: BRASIL. Ministério da Educação. Olimpíada de língua Portuguesa: escrevendo o futuro. São Paulo: Cenpec, 2010. Disponível em: <https://www.escrevendoofuturo.org.br/EscrevendoFuturo/arquivos/2447/20101201opiniao.pdf>. Acesso em: 20 maio 2017.

SEVERINO, A. J. Metodologia do trabalho científico. 23. ed.. São Paulo: Cortez, 2007.

SILVA, A. A. A argumentação em textos escritos por crianças em fase inicial do ensino fundamental. 2012. 141f. Dissertação (Mestrado Acadêmico em Letras) - Universidade do Estado do Rio Grande do Norte, Pau dos Ferros, 2012.

SOARES, F. L. B. de. A argumentação em artigos de opinião das Olimpíadas de Língua Portuguesa. 2015. 157 f. Dissertação (Mestrado Acadêmico em Letras) - Programa de Pós-Graduação em Letras, Universidade do Estado do Rio Grande do Norte, Pau dos Ferros, 2015.

SOUZA, G. S. Argumentação no discurso: questões conceituais. In: FREITAS, A. C.; RODRIGUES, L. O.; SAMPAIO, M. L. (Org.). Linguagem, discurso e cultura: múltiplos objetos e abordagens. Pau dos Ferros: Queima Bucha, 2008. p. 57-74. 
SOUZA, G. S. O Nordeste na mídia: um (des)encontro de sentidos. 2003. 403 f. Tese (Doutorado em Linguística e Língua Portuguesa)

- Faculdade de Ciências e Letras, Universidade Estadual Paulista Júlio Mesquita Filho, Araraquara, 2003.

SOUZA, G. S.; PEREIRA, C. C.; ALVES, M. L. Argumentação e dialogismo no texto acadêmico: os interlocutores em justificativas de monografias de graduação. In: HORA, D. da (Ed.). CONGRESSO INTERNACIONAL DA ABRALIN, 6., 2009, João Pessoa. Anais... João Pessoa: UFPB/ABRALIN, 2009. p. 1.642-1.647.

SOUZA, M. A Textos finalistas. Artigo de opinião: caderno do professor. In: BRASIL. Ministério da Educação. Olimpíada de língua Portuguesa: escrevendo o futuro. São Paulo: Cenpec, $2010 . \quad$ Disponível em: <https://www.escrevendoofuturo.org.br/EscrevendoFuturo/arquivos/2447/20101201opiniao.pdf.>. Acesso em: 20 maio 2017. 